\title{
Product Class Code
}

National Cancer Institute

\section{Source}

National Cancer Institute. Product Class Code. NCI Thesaurus. Code C94021.

A coded value specifying a group of products that are homogeneous or generally considered as substitutes for each other. The class is considered as narrow or broad depending on how substitutable the various products are. 